\title{
A SYNDROME RESEMBLING PROGERIA: A REVIEW OF TWO CASES
}

\author{
BY \\ CATHERINE A. NEILL, M.D., and MARY M. DINGWALL \\ From the Queen Elizabeth Hospital for Children, London
}

(Received for Publication July 29, 1949)

We are presenting two cases, which we consider to be examples of a syndrome allied to progeria, in some detail because no exactly similar cases appear to have been recorded.

These children were first seen at the Queen Elizabeth Hospital, Hackney, by Dr. Helen Mackay in June, 1947. They present strikingly similar clinical pictures, the outstanding features being dwarfism, microcephaly, a fine diffuse characteristic ' pepper and salt' choroido-retinitis, and intracranial calcification. The elder (A.P.) has recently developed deafness. They are both mentally defective. Their characteristic posture can be seen in Fig. 1, and Fig. 2 shows them compared with their normal sister.

\section{Family History}

The family history is essentially unrevealing but is shown in as much detail as is obtainable.
13 months on account of inability to walk and his condition was then diagnosed as infantilism. Thereafter he failed to grow normally and his mother thinks he is now smaller in the face and thinner than he was at 5 years old, and that his speech is less distinct and he talks less than at 7 years old.

Tremor was first noted when the child was 2 to 3 years old, and has persisted ever since, becoming more gross in the past year. His gait has always been unsteady, and he has fallen easily, especially in the past year.

When 6 years old (in 1939) he was admitted to the Queen Elizabeth Hospital, Shadwell, under Dr. O'Reilly, for failure to grow and backwardness in speech. His weight was $23 \frac{3}{4} \mathrm{lb}$; height $37 \mathrm{in}$; span 36 in. He had a coarse tremor described as of 'intention type'; he was said to look ' rather elderly'; and his hands and feet were relatively large; there was some pigmentation of the skin of the face, which was dry and wrinkled. He was microcephalic (head circumference $17 \frac{1}{4} \mathrm{in}$.), and already showed a tendency to valgus deformity of feet. A

\section{History of A.P.}

A.P., aged 16 years, the older and the more severely affected of the two, has been examined more frequently than his brother and has several times been admitted to other hospitals. $\mathrm{He}$ was born at home on March 7, 1933, following a normal pregnancy and labour and weighed $7 \frac{1}{2} \mathrm{lb}$. at birth. $\mathrm{He}$ was breast fed for seven months and seemed normal in early infancy. The mother is uncertain of his early milestones, but by 13 months he could crawl and sit up and say a few simple words. He cut his first tooth at over one year, fed himself at 16 months, and started to walk at $2 \frac{1}{2}$ years. The mother thinks he gained weight normally during the first year, but he was taken to Great Ormond Street Hospital at

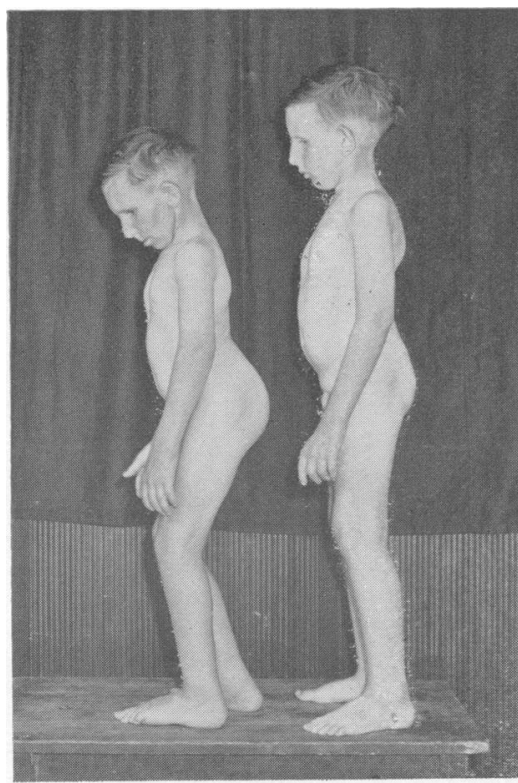

FIG. 1.-Characteristic posture.

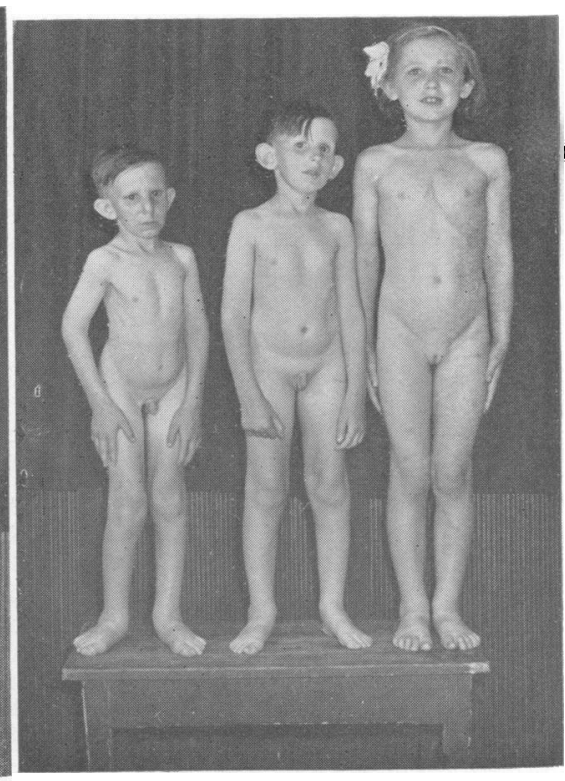

FIG. 2.-A.P. and J.P. compared with their normal sister. 
Genealogical Table of P. Family

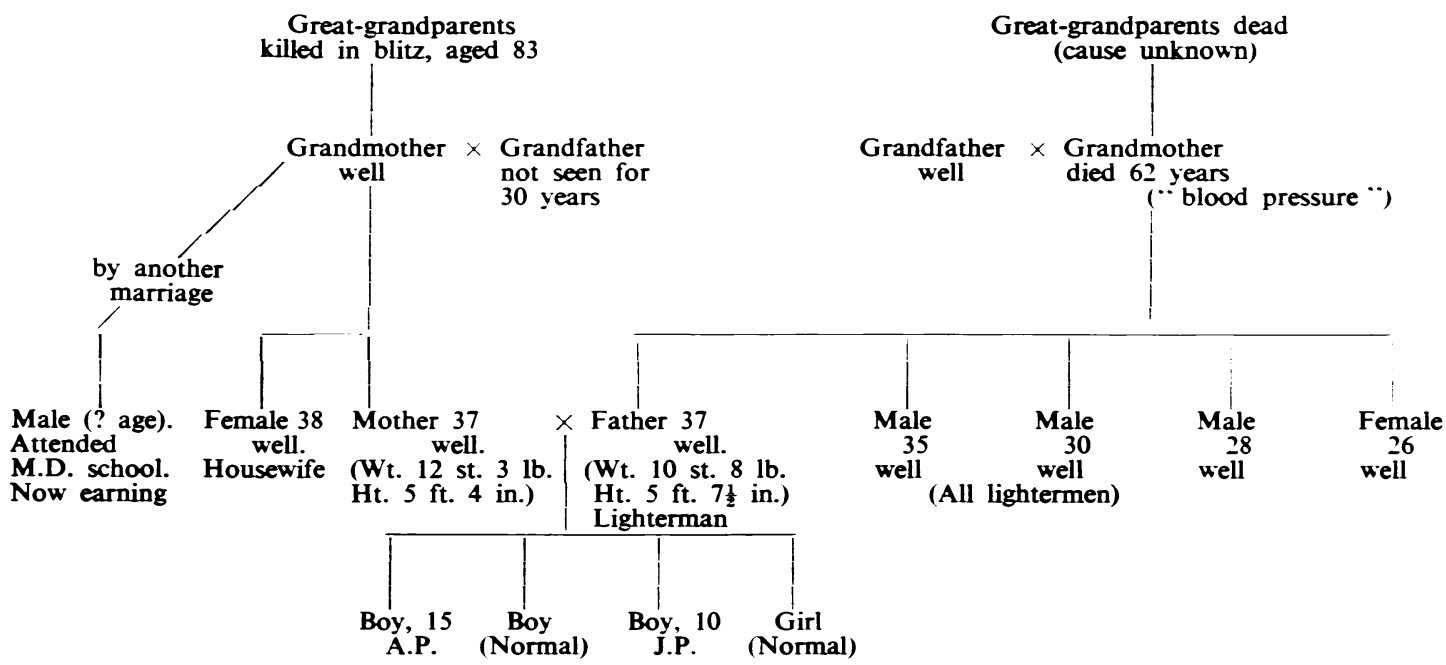

radiograph of the skull showed calcification, which was thought to be a calcified haemangioma. He was given some gonadal injections for undescended testes with no effect.

There is no note on his ocular fundi.

At 8 years old (in 1941) A.P. was medically examined and classified as ineducable. His defective articulation, insecure gait, and 'old man' appearance with sunken eyes were remarked on. He could use only a few short phrases, and could not count or read at all or copy signs. His mental age was assessed as 3 years 4 months.

His weight was $26 \mathrm{lb}$., his height $36 \frac{1}{2}$ in., and his head circumference 17 in. (Dr. Forbes).

At $12 \frac{1}{2}$ years (December, 1945) he was admitted to the West End Hospital for Nervous Diseases (Dr. Simpson). He was noted to be slightly deaf, and to have carious teeth, in addition to the points previously noted. The cerebrospinal fluid contained 13 cells per c.mm. (lymphocytes $96^{\circ}$ ) and $100 \mathrm{mg}$. protein. A radiograph of the skull showed trabecular calcification in both hemispheres, in the choroid plexus, and in frontal and parietal cortex.

When 15 years old (January, 1948) he was admitted to the Queen Elizabeth Hospital, Hackney, and the findings there are given below. He had been having fairly frequent pains in his legs and was falling more frequently. He was sometimes incontinent. Since his discharge in March, 1948, he has become quieter and more miserable with a frequent cough; he is now persistently incontinent. His deafness is now almost complete. He can still see near objects fairly well.

He has had measles, pertussis, chickenpox, pneumonia, and jaundice (four years ago).

\section{History of J.P.}

J.P., aged 11 years, was born on April 7, 1938. Pregnancy and labour were normal, and the birth weight was $8 \mathrm{lb}$. Infancy was normal. The first tooth appeared at over 12 months. He walked when he was about $2 \frac{1}{2}$ years old and his gait has always been unsteady. Tremor has been less severe than that of A.P., but has become more marked recently. His own doctor said when the child was $2 \frac{1}{2}$ years old that he would be like his brother A.P. He has, however, grown rather better than A.P., and remains larger and less microcephalic.

He was medically examined at 3 years and found to be ' undersized and shrunken,' with unsteady gait, gross tremor, and defective articulation. He was dry during the day; his large prominent ears were commented on. At $4 \frac{1}{2}$ years he showed excessive salivation, but this was much less by 7 years and is now not troublesome. Dental caries was marked by 6 years. His mental age at 7 years was assessed at less than 3 years. No radiographs of the skull were taken, nor comment made on the ocular fundi.

When $9 \frac{3}{4}$ years old he was admitted to the Queen Elizabeth Hospital, Hackney, and the findings there are given below. Since discharge in March, 1948, he has shown little change: his hearing is probably somewhat impaired. He is now more frequently incontinent than he was a year ago.

He has had measles, pertussis, scarlet fever, and pneumonia (two attacks).

\section{Clinical Examinations}

A.P. is of very small stature, the trunk particularly small, and the extremities relatively large. The legs appear long. There is lumbar lordosis, a slightly protuberant abdomen, pes valgus, and a fixed flexion deformity $\left(10^{-}\right)$of the knees. His gait is 'tottering ' and he falls fairly frequently. A coarse tremor (intentional type) is present. Pigmented moles are numerous on the head and neck, arms and legs. The child is microcephalic (i.e. head circumference small but no sloping of forehead), with prominent ears and sunken eyeballs. The skin of the face is stretched and shows some wrinkling, but elsewhere is of normal texture, although it is 
rough and rather dry on the hands and feet. The hair is dry and thin and a little scanty. The eyebrows and lashes are normal (Fig. 3).

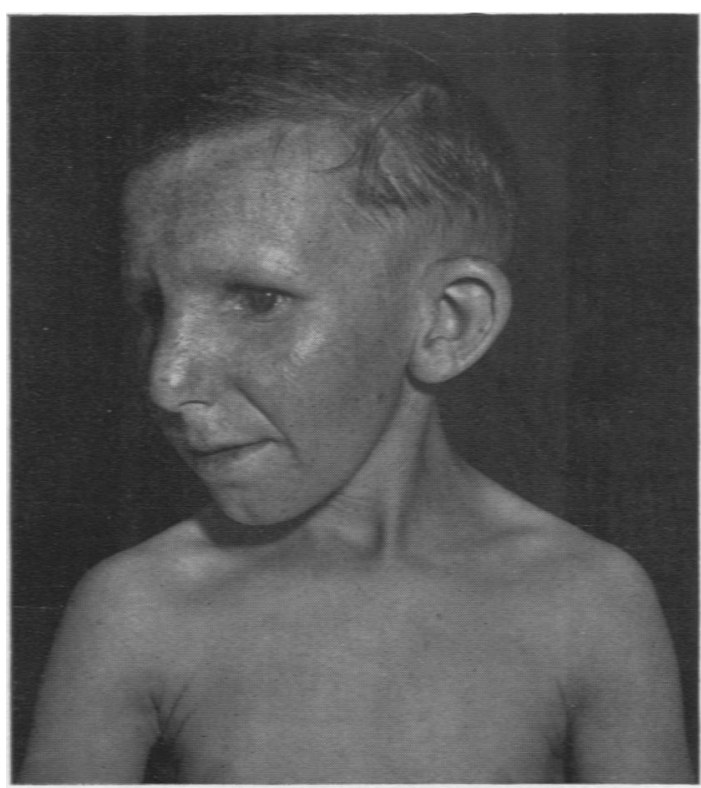

Fig. 3.-Photograph of A.P.

Cardiovascular System. No arteriosclerosis in January, 1948, but by November, 1948, shows definite arterial thickening. Heart not enlarged. Aortic second sound accentuated. Blood pressure 12070.

Respiratory SySTEM. Normal; chest expansion slight.

Digestive System. Teeth irregular, grossly carious, some missing (see $\mathrm{x}$-ray reports). Gums hypertrophied.

ABDOMEN. In January, 1948, liver enlarged one finger below costal margin (increased to two and a half fingers by November, 1948). Spleen enlarged two fingers below costal margin.

Urogentral System. Bilateral undescended testes. No secondary sex characteristics.

Central Nervous System. Pupils slightly irregular; very small; react very slightly to light and accommodation; very slow response to mydriatics. Other cranial nerves appear normal, apart from rapidly increasing deafness for past year now almost complete. Limbs stiff but not definitely spastic. Jerks brisk. Plantars flexor.

Fundi show 'degenerative retinitis of the pepper and salt type. Advanced optic atrophy both eyes.' (Mr. J. Minton, F.R.C.S.)

J.P. The clinical picture is in general very similar to that of A.P. J.P. is less severely affected (Figs. 1 and 2). He is slightly talker, and looks paler, with less wrinkling and pigmentation. His ears are more prominent. His posture is less abnormal.

The spleen is only just palpable; liver one fingerbreadth; blood pressure 11260 . No evidence of arteriosclerosis. Teeth less carious. Optic atrophy less marked but retinae similar.

\section{Measurements}

The children were measured in January, 1948, and their measurements compared with those of their normal brother aged 13 years (Table 1).

Re-measuring in November, 1948, showed a slight decrease in A.P.'s height ( 2 in.) probably due to increased lordosis and flexion.

\section{Laboratory Investigations}

Blood. Full laboratory investigations were made in January, 1948, and the results are set out as follows (Tables 2 and 3).

Toxoplasmosis Tests.-Dr. Sven Gaard (Stockholm) tested the serum of A.P. and Mrs. P. for toxoplasma

Measurements of A.P. ANd J.P. compared With those of their Normal Brother

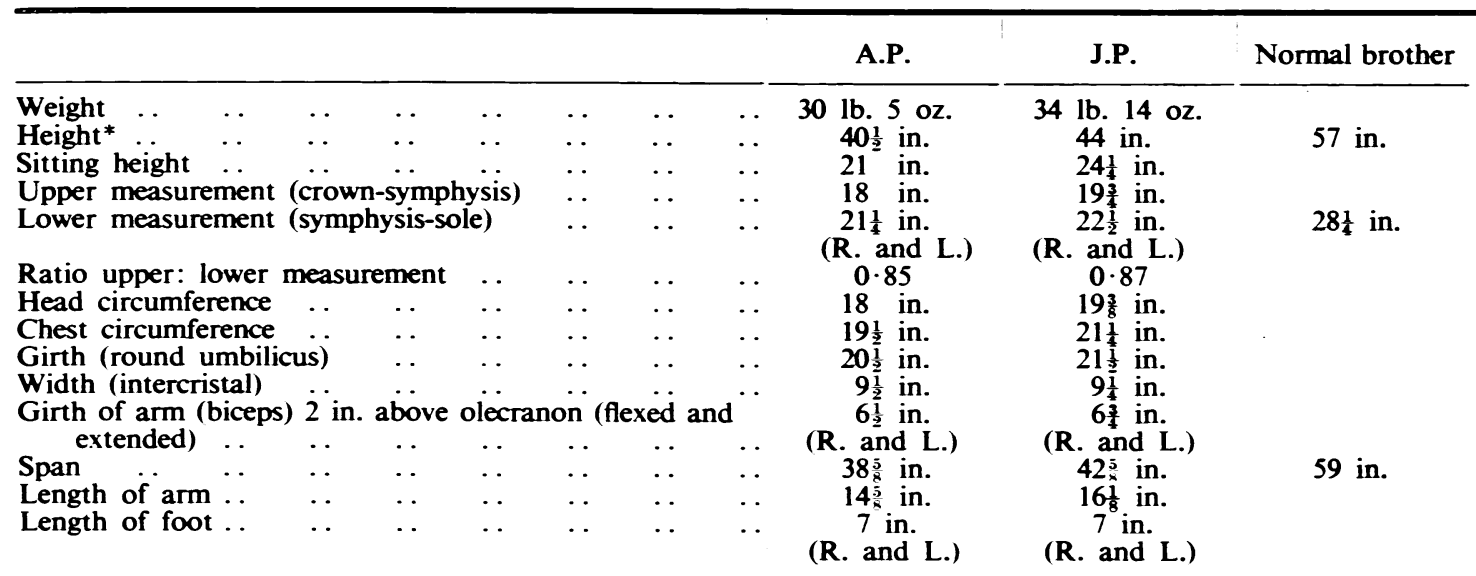

* Measurements of height, etc., are approximate only, as the lordosis and fixed flexion of the knees make complete accuracy impossible. 
TABLE 2

RESULTS OF LABORATORY INVESTIGATIONS

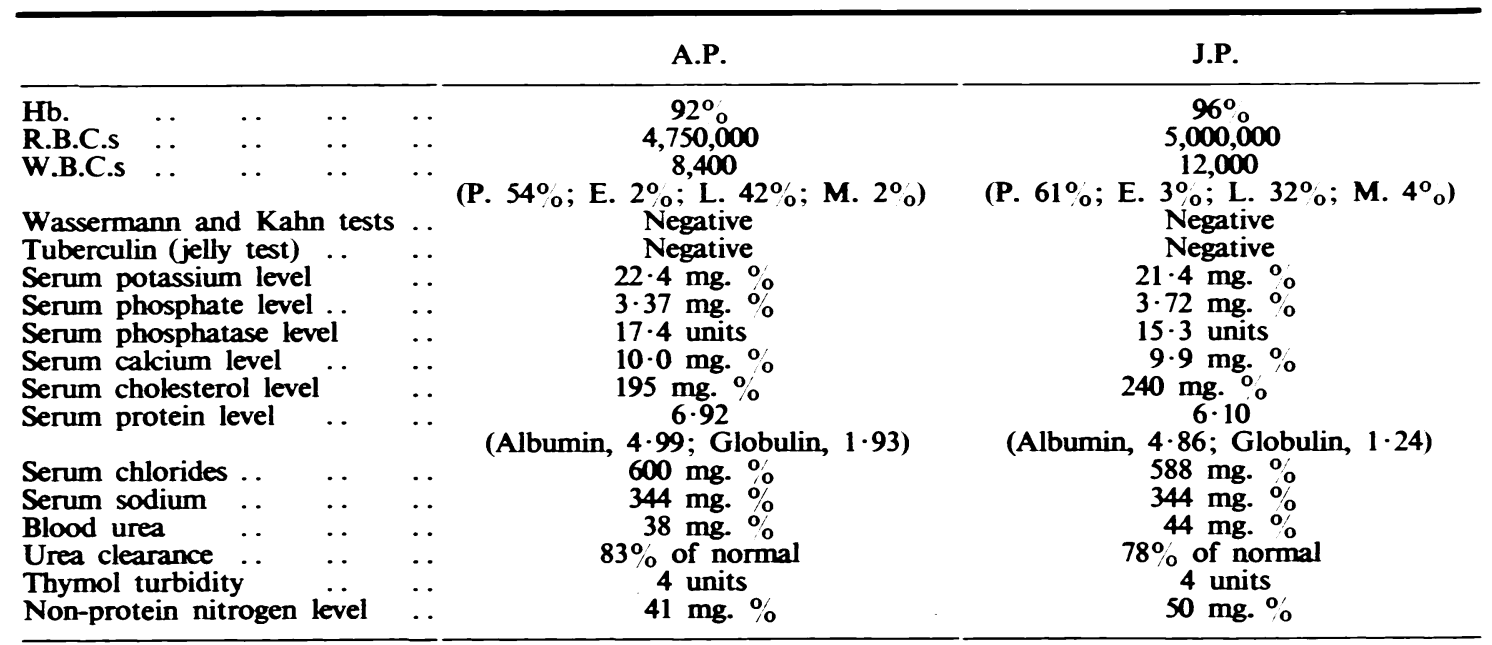

Urine

Acid (yellow).

Protein: very faint trace.

Sugar: nil.

Deposit: n.a.d.

Urinary amino-acid nitrogen ..

$44 \mathrm{mg}$. $100 \mathrm{ml}$.

(Both within normal limits)

Acid (yellow).

Protein: nil.

Sugar: nil.

Urinary 17-ketosteroids (Dr. Patterson, Charing Cross Hospital) .. .. ..

$2 \cdot 0 \mathrm{mg} \cdot 24$ hours

(Both low values)

Deposit: n.a.d.

$94 \mathrm{mg} .100 \mathrm{ml}$.

$1 \cdot 1 \mathrm{mg} / 24$ hours

TAPLE 3

Sugar Tolerance Test (1 1 g. $/ \mathrm{kg}$.)

\begin{tabular}{lllllllllll}
\hline & & & & & & \\
\end{tabular}

antibodies. That of A.P. was negative, and that of the mother gave a titre of $1: 40$ which is not significant.

Tests for toxoplasmosis were also made at the Hospital for Sick Children, Great Ormond Street, by Dr. J. A. Dudgeon and Dr. I. A. B. Cathie on J.P., A.P., M.P. (sister), and Mrs. P. (mother). Their report is as follows (April 13, 1950).

Neutralization Test (Sabin, 1942). The results on all four members of the family were negative.

Complement Fixation Test (SABn, 1949). The results on all four members of the family were negative, using a purified antigen as suggested by Sabin.

Toxoplasmin SkIn Test (Frenkel, 1948). The results on all four members of the family were negative at 1100 .

Dye Test (Sabin and Feldman, 1948). This test was negative on J.P. and A.P. and positive at 116 on M.P. and Mrs. $P$. In our experience such titres do not appear to be significant.

Urinary amino-acids on chromatographic separation show no abnormality. 


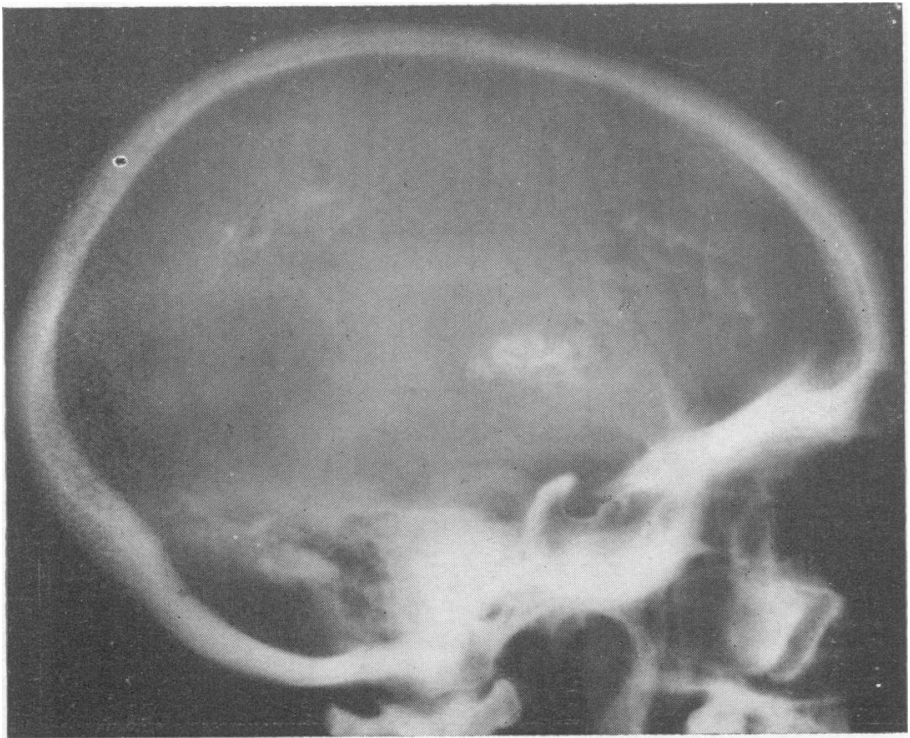

FIG. 4.-Lateral radiograph of skull of A.P., showing distribution of calcification.

\section{Radiological Investigations}

A.P. 'The skull as a whole is small, normally proportioned and with a thick calvarium. There are several scattered areas of calcification whose exact siting depends on the relation of the ventricular systems to the actual brain tissue. There is some evidence that the former may be dilated.

There are three main areas of calcification: (1) Two bilateral disc-shaped areas of mottling lying just lateral to the anterior horns of the lateral ventricles, presuming these are normal in size and position; (2) bilateral calcification apparently in the dorsum sellae and tentorium cerebelli regions; (3) bilateral calcification in the lateral, frontal, and middle parietal regions which is probably near the surface of the skull and may actually be in the cortex or meninges. Its distribution suggests that it follows the cerebral convolutions. Thus each area of calcification could conceivably lie in the meninges or the walls of dilated ventricles.

The sella turcica is normal.'

- The bones as a whole are smaller and more slender than usually found in this child's age group. There is slight general osteoporosis of the extremities. The bone age is within normal limits, however. There is well marked differentiation between cortex and medulla and the only structural abnormality apart from their size is a slight generalized coarseness of the trabeculae.'

DENTITION.- ' Left lower 6 and right lower 6 roots are present and show chronic apical abscesses. Upper left $6,4,3$, and upper right 3 show advanced dental caries. Upper left 4 is unerupted. Upper left 2 and 1 and upper right 1 and 2 have been extracted. The state of the dentition is normal for a boy aged 15.'

J.P. 'General appearance of the skull is similar to that of A.P. and the calcification appears to be in similar positions but is less gross.'
Bones show essentially similar changes to those of A.P.' (Dr. C. J. Hodson.)

DENTITION.-Upper right 5 and upper left 5 are absent. Upper left $\mathrm{c}$ and upper right $\mathrm{c}$ and lower left $\mathrm{c}$ and lower right $c$, d, and e are the only deciduous teeth present and they have complete root absorption. No evidence of periapical infection. The state of the dentition is within normal limits for a boy of 10 years.

\section{Mental State}

Intelligence tests were given to all four children in this family.

The second and fourth child (boy and girl) are of average intelligence according to the test results (boy aged 13 years 11 months: I.Q. 106; girl aged 7 years 8 months: I.Q. 109).

A.P., whose chronological age is 15 years, has a mental age of 2 years 3 months. This was established by the Merrill Palmer test (2 years 3 months); the revised Stanford Binet test (2 years 3 months); and Gesell's norms (2 years 5 months).

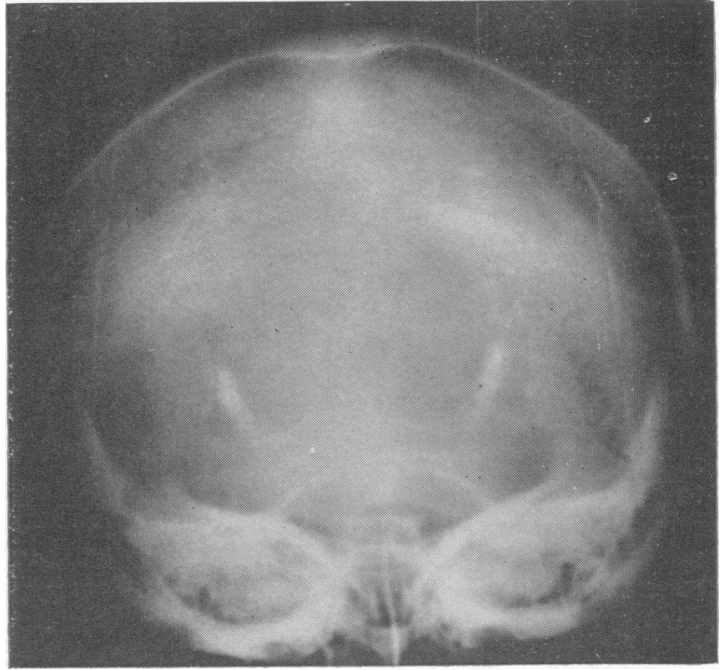

FIG. 5.-Antero-posterior view of skull of A.P.

J.P., whose chronological age is 9 years 11 months, has a mental age of almost $2 \cdot 1$ years, the three tests showing a difference of one month (Merrill Palmer, 2 years 5 months; revised Stanford Binet, 2 years 4 months; Gesell's norms, 2 years 6 months).

Both children are classifiable as idiot. J.P. makes a slightly higher score than A.P. A.P.'s intelligence may have regressed a little in the last few years. There are some indications that both children have regressed since first tested in June, 1947. This may be due to their period in hospital, and be temporary, or it may be an actual lessening of intellectual ability. The parents and teachers support the latter view. 


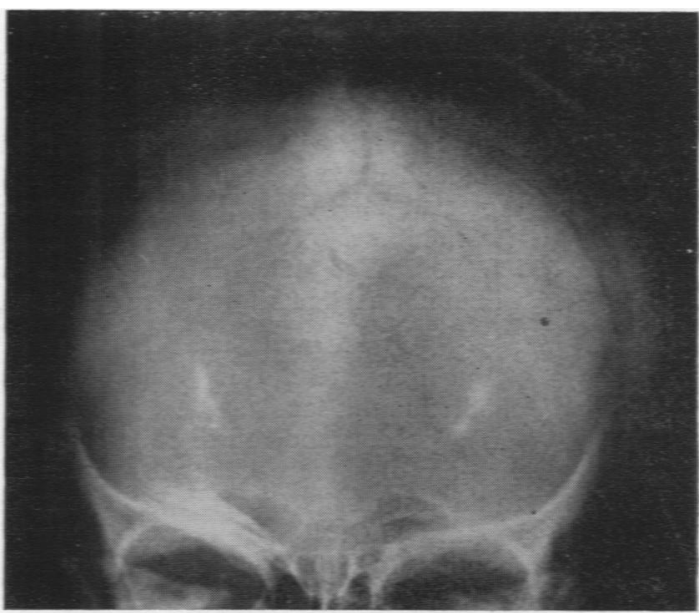

FIG. 6.-Antero-posterior view of skull of J.P.
J.P. has shown little change apart from increasing incontinence. His eyes are rather more sunken but his weight is being maintained. There is probably slight difficulty in hearing but nothing approaching complete deafness.

\section{Discussion}

The outstanding clinical features of these two brothers appear to be (1) the similarity to each other, and difference from the rest of the family; (2) the appearance, which is a compound of dwarfism and apparent senility, an exceptionally small trunk with disproportionately longer extremities, a very small head (not showing the usual stigmata of microcephaly), a characteristic posture, a coarse intention tremor, and a rather tottering gait. They show some pigmentation, which is not gross, some loss of subcutaneous fat, most marked on the face, and a gross degree of sexual infantilism; (3) the degenerative retinitis with fine, widespread pigmentation over

Although both children are idiots their behaviour is unlike that of idiots of their age. Both children play very like normal 2-2! year-olds, except that they cannot rush wildly around, but they have all the joviality, warm human affections and interest in life of the typical 2-3 yearold. They can be very jealous. One makes a much closer contact with them than one usually does with idiots and imbeciles, or possibly even high grade defectives of their chronological age. Their social adaptation is very good and this accounts for the slightly higher score achieved by both on Gesell's norms. This good social adaptation may be due to the fact that there are two of them; to the parents who have made a united affectionate family out of some oddly assorted children; the idiocy appears to be secondary and so the impulse to grow and develop would be stronger in the first few years than in cases of primary idiocy. In contrast to their general emotional reactions which are on the $2 \frac{1}{2}$ year-old level their hand movements are almost adult. This is probably due to practice and maturation.

There is an obvious difference in personality between the two children. A.P. is the more forthcoming, the extrovert; J.P. is silent and retiring, the introvert.

The detailed results of intelligence tests are appended for future comparison with any similar case.

During the past year (January, 1948, to January, 1949) A.P. has developed definite arteriosclerosis, and is undoubtedly becoming weaker and less happy: he has also become almost completely deaf and completely incontinent. He has frequent coughs and bronchitis and is generally frailer.

He has had one or two attacks of loss of consciousness but no definite convulsions. There have been no anginal attacks.

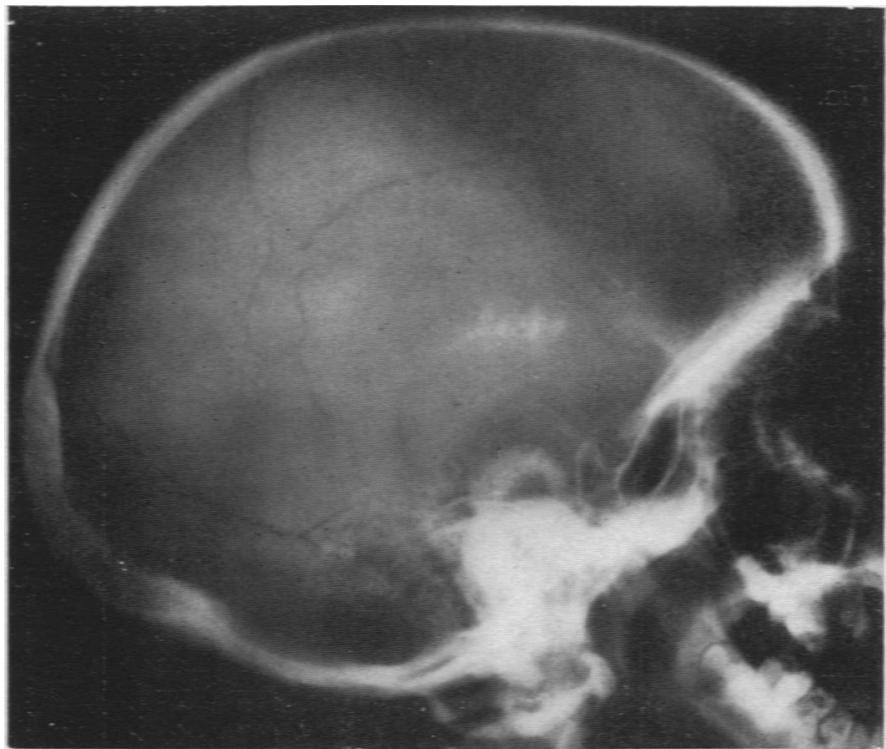

Fig. 7.-Lateral radiograph of skull of J.P. showing less extensive calcification.

the whole fundus, and a fairly advanced optic atrophy. The appearance is exactly similar to that of Cockayne's cases (1936); (4) the intracranial calcification, which is extensive, situated chiefly in the neighbourhood of the choroid plexuses but also in the frontal region; (5) the apparent hepatomegaly in both, and the splenomegaly in the older child only; (6) the idiocy.

These features do not appear to fit into any welldefined syndrome, but the two brothers show a marked resemblance to two cases published by Cockayne in 1936 and re-described in 1946 as 
Dwarfism with Retinal Atrophy and Deafness. These patients were a brother and sister, aged respectively 6 and 7 years in 1936, two of seven siblings all the rest being normal. They were grossly dwarfed, underweight, with small heads similar in shape to those of the two patients described. They showed an exactly similar type of retinal degeneration: his two cases were greatly mentally retarded, but their mentality was difficult to assess. By 1946 both were blind from optic atrophy, and had bilateral cataracts. They were also by this time completely deaf, having been only slightly deaf in 1936. Cockayne found no reference to previous similar cases, and discusses the differences between his cases and retinitis pigmentosa. He states that the type of pigmentation is essentially finer and more diffuse than in retinitis pigmentosa and there are none of the large ' bone corpuscle' deposits of pigment characteristic of the latter condition. And although retinitis pigmentosa may be associated with deafness, epilepsy and mental deterioration, it has never been recorded associated with dwarfism and microcephaly. His cases differ from ours in having cataracts, and in the absence of intracranial calcification and of hepatosplenomegaly; but despite these considerable differences, there seems little doubt that they are essentially the same condition. Cockayne did not comment on any possible relationship between his cases and progeria, but there are some important similarities.

Progeria was first described by Hutchinson in 1886 . Gilford in 1904 re-described Hutchinson's case, who had by that time died at the age of 17 years, and gave another case of his own. He originally called the condition micromegaly (because of the contrasts it presented to acromegaly), but later called it progeria. Since then about 20 classical cases have been described, and a number of others showing similarities but not completely typical. The classical picture is well shown in a photograph of Gilford's case (Thomson and Forfar, 1950; see Fig. 2, p. 224.)

The essential features are dwarfism, loss of hair, an old appearance, loss of subcutaneous fat, a dry stretched skin showing some wrinkling, arthritis producing the typical posture, osteoporosis, and arteriosclerosis. The last named is the usual cause of death, which may occur from coronary disease or a cerebral vascular accident before the age of 20 . The mentality is usually said to be normal or slightly low, but there are no gross mental defectives among th: classical cases. Our two cases show the following points in common with progeria: (1) onset of dwarfism at about one year of age; (2) senile appearance; (3) mild arthritis; (4) osteoporosis; (5) stretching of the skin of the face and some pigmentation of the skin; (6) calcification of blood vessels. They differ from progeria in (1) their gross mental deficiency; (2) microcephaly, the head circumference in progeria being smaller than normal for the age, but relatively large for the size of the body; ( 3 ) retinal degeneration; (4) disproportionate size of extremities; (5) intracranial calcification; and (6) the presence of hair. Baldness is the rule in the classical cases, but is not an essential feature, and there are, for instance, two cases of Schondel's (1943) where hair was present though rather scanty; Schondel's two cases also showed microphthalmos, in contrast to the usual slightly exophthalmic picture. Her article contains an excellent review of the literature and divides the described cases into classical and atypical.

In one or two points, such as their slightly abnormal sugar tolerance and the presence of 
calcification of the blood vessels our two cases resemble Werner's syndrome or 'progeria of the adult.'

We have attempted to show the points of differential diagnosis in the following chart, amended slightly from Thannhauser (1945).

Another condition that needs to be considered is toxoplasmosis. The intracranial calcification is coarser and more diffuse in our two cases than that usually described and the retinal changes are not characteristic. The serological reactions do not support the diagnosis. It is also difficult to envisage any maternal infection producing this particular family distribution of disease.
The most probable theory seems to be that the two dwarfs represent a multiple germ plasm defect, similar to that of progeria, possibly caused by a recessive gene and producing secondary extensive endocrine and metabolic disorders.

\section{Summary}

Two microcephalic dwarf brothers are described, with details of the physical and psychological investigations.

Reasons are advanced for suggesting that they are cases of multiple germ plasm defect, probably due to a recessive gene, and that this condition is allied to progeria.

TABLE 4

Chnical features of Varrous 'Multiple Germ-Phase Defect' Diseases

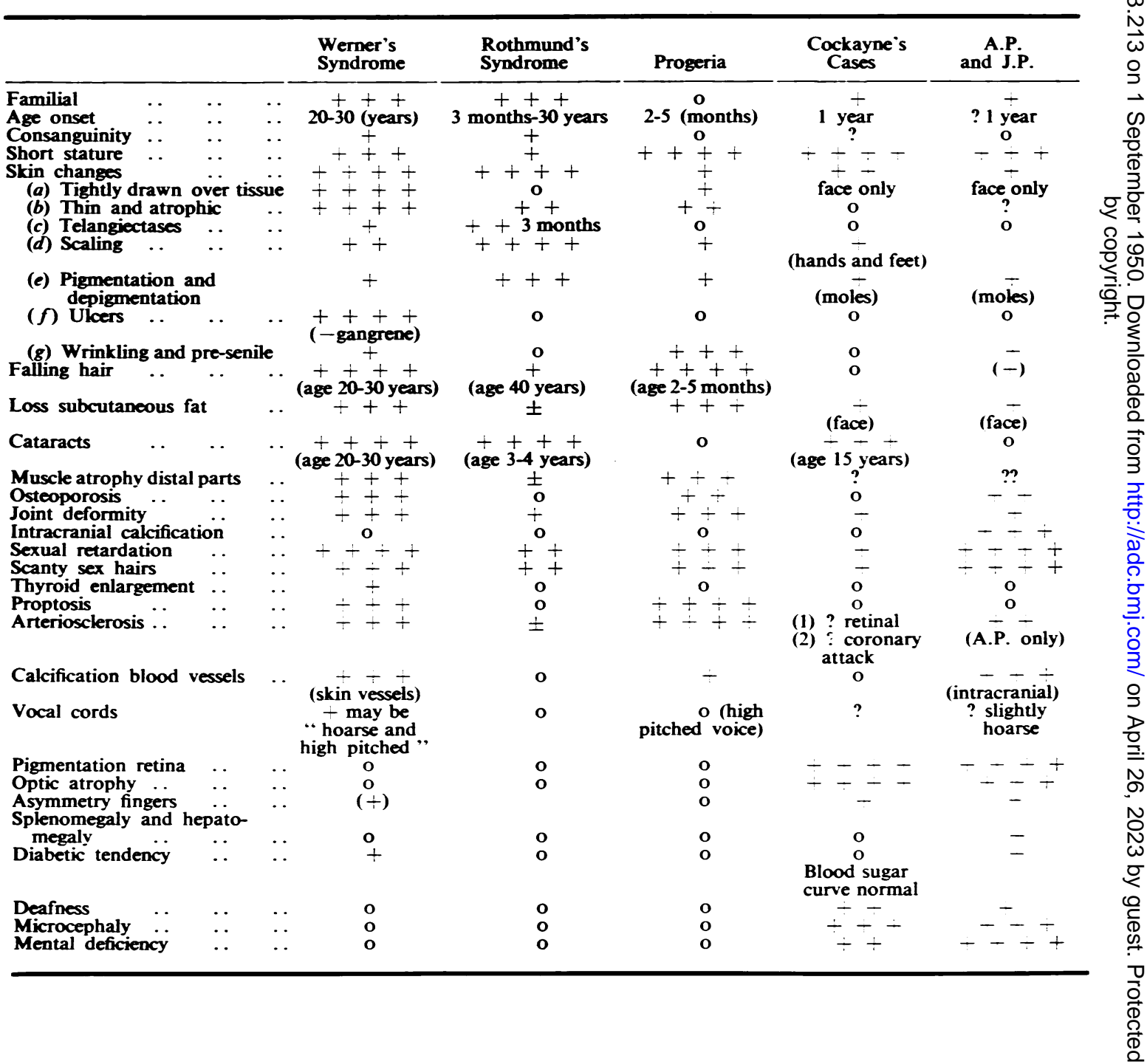


We are most grateful to Dr. Helen Mackay for allowing us to publish these two cases, and for her stimulus and encouragement, and to Dr. B. Levin for the investigations he has carried out. We are also very grateful to Dr. Wyndham Pearce for the interest he has shown, and we should like to thank all those mentioned in the article who have made special investigations for us.

\section{REFERENCES}

These cases were briefly published in the Proceedings of the Royal Society of Medicine, Vol. 41, No. 6, June 1948, pp. 349-50.

Broc, R., Nicolle, M., and Jaubert de Beaujeu, A. (1935). Pr. méd., 43, 786.

Cockayne, E. A. (1936). Arch. Dis. Childh, 11, 1. (1946). Ibid., 21, 52.

Frenkel, J. K. (1948). Proc. Soc. exp. Biol., N. Y., 68 634.
Gilford, H. (1904). Practitioner, 73, 188.

Hutchinson, J. (1886). Med. chir. Trans., 69, 473.

Manschot, W. A. (1940). Ned. Tijd. Geneesk., 84, 3774.

Mitchell, E. C. and Goltman, D. W. (1940). Amer. J Dis. Child.. 59, 379.

Sabin, A. B. (1942). 'Advances in Pediatrics.' Vol. I. New York. (1949). 'Pediatrics.' Vol. 4, 443.

- and Feldman, H. A. (1948). Science, 108, 660. Schondel, A. (1943). Acta pediatr., Stockh., 30, 286.

Talbot, N. B., Butler, A. M., Pratt, E. L., MacLachlan, E. A., and Tannheimer, J. (1945). Amer. J. Dis. Child., 69, 267.

Thannhauser, S. J. (1945). Ann. intern. Med., 23, 559626.

Thomson, J., and Forfar, J. O., (1950). Arch. Dis. Childh., 25, 224.

Variot and Pironneau (1910). Bull. Soc. Pédiat., Paris, 12, 431. 


\section{A P P E N D I X}

The Merril Palmer and Binet intelligence scales are tests of mixed type and many of the test items at the low age levels (i.e. under 5) are performance tests. Some test items are pass or fail: others are measured in both speed and accuracy.

Gesell's test uses norms of development based on studies of many young children, and the way in which they walk, talk, handle materials, etc. at different age levels,

The three tests were used for the sake of accuracy as well as interest. Only those items in which A.P. and J.P. were successful have been recorded here.

\section{MERRIL-PALMER SCALE: TEST ANALYSIS}

\begin{tabular}{|c|c|c|c|}
\hline & & A.P. & J.P. \\
\hline $\begin{array}{l}\text { Date examined } \\
\text { Chronological age } \\
\text { Mental age } \\
\text { Score } \quad \ldots\end{array}$ & $\begin{array}{ll}\cdots & \cdots \\
\cdots & \cdots \\
\cdots & \cdots \\
\cdots & \cdots\end{array}$ & $\begin{array}{l}\text { January } 1,1948 \\
14 \text { years } 10 \text { months } \\
2 \text { years } 5 \text { months } \\
18\end{array}$ & $\begin{array}{l}\text { January } 1,1948 \\
9 \text { years } 9 \text { months } \\
2 \text { years } 5 \text { months } \\
23\end{array}$ \\
\hline 18 to 23 months. & $\cdots$ & $\begin{array}{l}\text { Throwing ball } \\
\text { Straight tower } \\
\text { Questions } \\
\text { Wallin peg board A } \\
\text { Walking block } \\
\text { Crossing feet } \\
\text { Sixteen cubes } \\
\text { Repetition of words } \\
\text { Standing on one foot }\end{array}$ & $\begin{array}{l}\text { Commands Test } \\
\text { Throwing ball } \\
\text { Straight tower } \\
\text { Questions } \\
\text { Wallin peg board A } \\
\text { Walking block } \\
\text { Crossing feet } \\
\text { Sixteen cubes } \\
\text { Repetition of words } \\
\text { Folding paper }\end{array}$ \\
\hline 24 to 29 months & $\cdots$ & $\begin{array}{l}\text { Sixteen cubes } \\
\text { Wallin peg board A } \\
\text { Drawing up string } \\
\text { Cutting with scissors }\end{array}$ & $\begin{array}{l}\text { Identification of self in mirror } \\
\text { Sixteen cubes } \\
\text { Wallin peg board A } \\
\text { Drawing up string } \\
\text { Nest of cubes } \\
\text { Cutting with scissors }\end{array}$ \\
\hline 30 to 35 months & & $\begin{array}{l}\text { One button } \\
\text { Three cube pyramid }\end{array}$ & $\begin{array}{l}\text { Sixteen cubes } \\
\text { Three cube pyramid } \\
\text { Nest of cubes } \\
\text { Closing fist and moving thumbs }\end{array}$ \\
\hline 36 to 41 months & & $\begin{array}{l}\text { Copying circle } \\
\text { Little pink tower } \\
\text { Three cube pyramid }\end{array}$ & $\begin{array}{l}\text { Copying circle } \\
\text { Three cube pyramid }\end{array}$ \\
\hline 42 to 47 months & & - & Three cube pyramid \\
\hline
\end{tabular}

REVISED STANFORD BINET INTELLIGENCE SCALE (FORM L)：TEST ANALYSIS

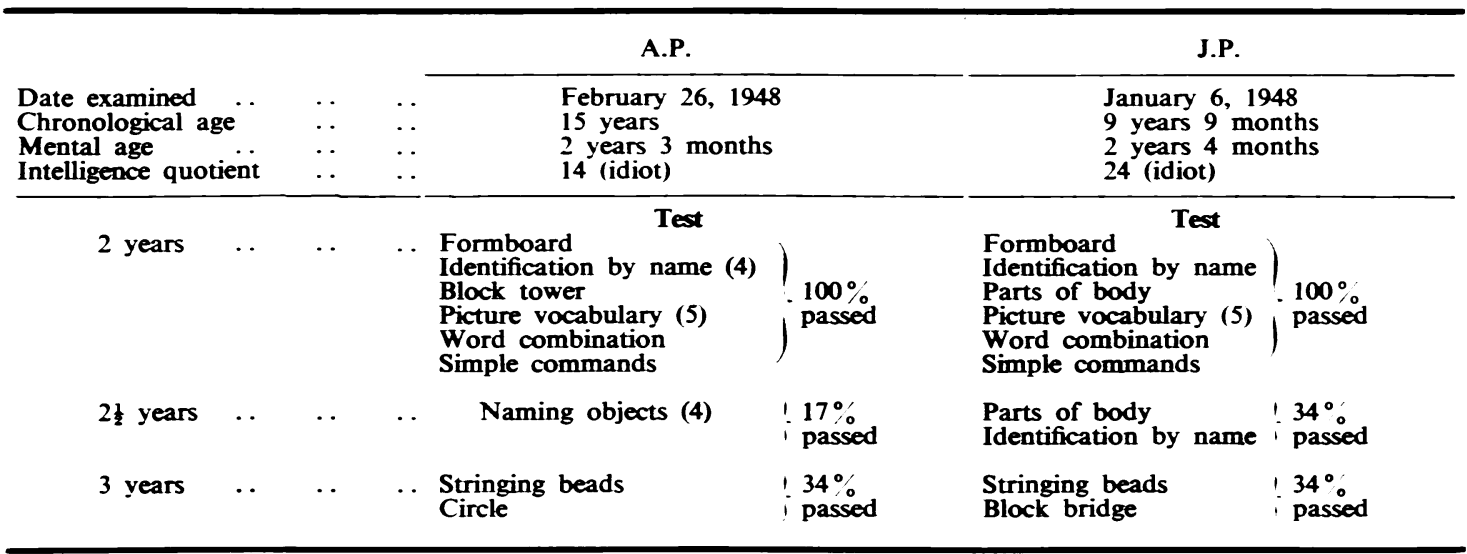




\section{GESELL'S NORMS : TEST ANALYSIS}

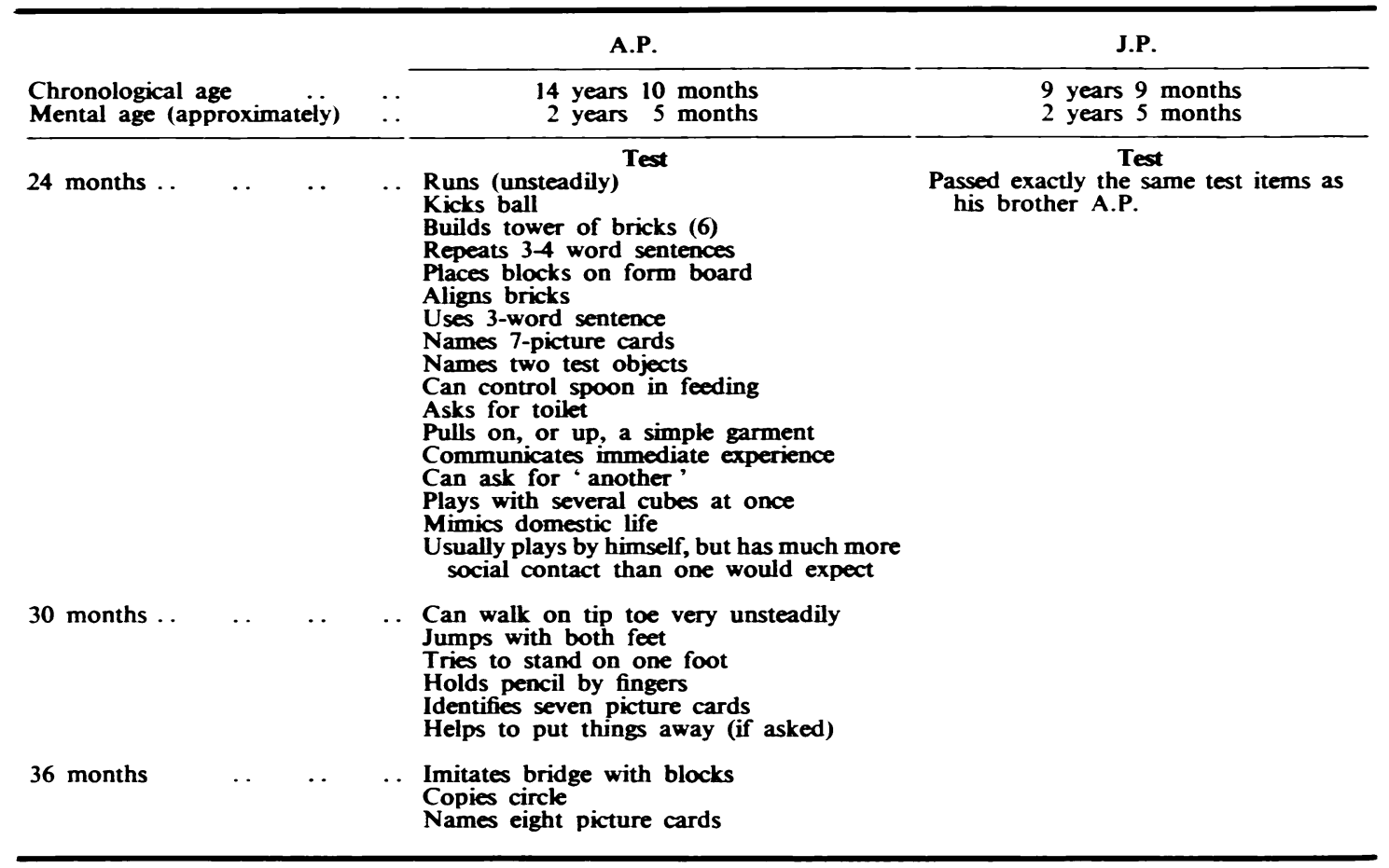

